\title{
AVALIAÇÃO DA CAPACIDADE ADSORTIVA DE CARVÃO ATIVADO PARA A REMOÇÃO DE MANGANÊS
}

\author{
T. A. G. PERILLI', D. C. SICUPIRA ${ }^{2}$, M. B. MANSUR ${ }^{2}$ e A. C. Q. LADEIRA ${ }^{1}$ \\ ${ }^{1}$ Centro de Desenvolvimento da Tecnologia Nuclear \\ ${ }^{2}$ Universidade Federal de Minas Gerais \\ thomazperilli@yahoo.com.br - dsicupira@yahoo.com.br-marcelo.mansur@demet.ufmg.br-acql@cdtn.br
}

Artigo submetido em novembro/2013 e aceito em abril/2014

DOI: http://dx.doi.org/10.15628/holos.2014.1777

\section{RESUMO}

A possibilidade de remoção de manganês contido em efluentes de mineração de elevada concentração, i.e., até $140 \mathrm{mg} / \mathrm{L}$, foi estudada através de adsorção em carvão ativado. Inicialmente, foi feito um tratamento térmico no carvão em duas temperaturas distintas, com o intuito de avaliar a importância dos sítios de adsorção no processo. Os ensaios de adsorção foram conduzidos em batelada, utilizando-se uma solução de laboratório para simular os altos níveis de manganês típicos de drenagem ácida de mina. Os resultados mostraram que os carvões tratados termicamente apresentaram queda de capacidade adsorvente. Análises da superfície específica dos materiais e do ponto de carga zero apontam para um mecanismo de quimiossorção, em acordo com o mecanismo de troca catiônica proposto em outros estudos. A decomposição de sítios ativos de adsorção durante o tratamento térmico pode explicar a redução na remoção do manganês entre os carvões tratados e o carvão in natura. Em nenhum dos casos testados a solução atingiu a concentração permitida pela legislação brasileira, de $1 \mathrm{mg} / \mathrm{L}$, sendo o melhor resultado $20 \mathrm{mg} / \mathrm{L}$.

PALAVRAS-CHAVE: manganês, drenagem ácida de mina, adsorção.

\section{EVALUATION OF ADSORPTIVE CAPACITY OF ACTIVATED CARBON FOR THE REMOVAL OF MANGANESE}

\begin{abstract}
The possibility of removing manganese contained in mining effluents with high concentrations, i.e., up to $140 \mathrm{mg} / \mathrm{L}$, was studied by adsorption on activated carbon. Initially, a heat treatment was done at two different temperatures on charcoal, in order to assess the importance of the adsorption sites in the process. The adsorption experiments were conducted batchwise using a solution of laboratory to simulate the high levels of manganese typically found in acid mine drainage. Results showed that both heat-treated coals had their adsorbent
\end{abstract}

capacity decreased. Analysis of the specific surface of all three materials and point of zero charge points to a chemisorption mechanism, in agreement with the mechanism of cation exchange proposed in other studies. The decomposition of active sites during heat treatment may explain the decrease in manganese removal from treated coals regarding untreated coal. In none of the cases tested the solution reached the concentration allowed by Brazilian legislation of $1 \mathrm{mg} / \mathrm{L}$, with the best result being only $20 \mathrm{mg} / \mathrm{L}$.

KEYWORDS: manganese, acid mine drainage, adsorption. 


\section{INTRODUÇÃO}

A drenagem ácida de mina (DAM) é resultado da oxidação natural de minerais portadores de enxofre quando expostos à ação combinada da água e do oxigênio, em geral na presença de bactérias, criando um ambiente de elevada acidez capaz de promover a lixiviação de metais da matriz rochosa. É um problema recorrente em minas de $\mathrm{Cu}, \mathrm{Zn}, \mathrm{Ni}$, ouro, urânio e carvão (Sicupira, 2012). No Brasil, um importante foco da drenagem ácida encontra-se no Planalto de Poços de Caldas (MG), cujas atividades de lavra, beneficiamento e tratamento químico de minério de urânio foram finalizadas em 1995. O sítio de mineração agora se encontra em fase de descomissionamento (Santos e Ladeira, 2011). Um dos principais problemas para o tratamento dos efluentes oriundos desta drenagem é o manganês, que pode ser encontrado em concentrações próximas a $140 \mathrm{mg} / \mathrm{L}$. A resolução do CONAMA (Conselho Nacional do Meio Ambiente) $\mathrm{n}^{\circ} 430$ estabelece o limite para o descarte de manganês no ambiente em $1 \mathrm{mg} / \mathrm{L}$. Também estabelece que o pH deva situar-se entre 5 e 9 para que o efluente possa ser descartado.

A remoção de metais pesados de efluentes é usualmente feita através de precipitação dos metais na forma de hidróxidos, seguida por filtração e descarte do precipitado. No entanto, essa técnica apresenta algumas desvantagens, como ineficiência do processo caso os metais estejam complexados ou na forma de ânions, limitação da concentração do metal remanescente devido à solubilidade, e quantidade de lodo gerada. A necessidade de uma etapa posterior para a remoção dos sólidos e clarificação da água é outro ponto negativo (Madeira et alii, 2008). O processo atual de remoção do manganês utilizado na região de Poços de Caldas requer uma quantidade significativa de cal e gera grande quantidade de precipitado, resultando em elevado custo operacional e ambiental. Além disso, a precipitação ocorre em pH muito alto ( 10), havendo a necessidade de correção deste para descarte do efluente. Assim, faz-se necessário uma otimização do processo ou o desenvolvimento de métodos alternativos.

Uma possibilidade que vem sendo bastante estudada para a remoção de metais dos efluentes é o uso de um adsorvente. A adsorção de metais pesados mostrou-se eficiente para condições menos alcalinas do que aquelas empregadas na precipitação. A adsorção permite a remoção de cátions metálicos mesmo que complexados, e atinge teores de metais muito inferiores aos da precipitação, já que não possui problemas de solubilidade. Outras vantagens apontadas são a redução severa da quantidade de lodo gerado e o baixo custo, caso não haja necessidade de regeneração do adsorvente (Madeira et alii, 2008).

O carvão é um adsorvente de eficácia comprovada na remoção de metais pesados e outros compostos tóxicos de efluentes industriais (Mishra et alii, 2010). O carvão ativado (CA) é um material microporoso de elevada área superficial $\left(>500.000 \mathrm{~m}^{2} / \mathrm{kg}\right)$ e pode acomodar em sua estrutura elementos como oxigênio, nitrogênio e hidrogênio, responsáveis pela formação de grupos funcionais. Essas características conferem ao CA elevado poder adsorvente, tanto física quanto quimicamente. Seu desempenho depende principalmente de seu tipo, da competição de substâncias orgânicas naturais e do tempo de contato na estação de tratamento. É possível alterar o carvão de forma a melhorar a seletividade do processo, via tratamento térmico, oxidação ou impregnação com compostos orgânicos e inorgânicos. (Guilarduci et alii, 2006). 
Quando um sólido como o carvão é imerso em um ambiente líquido, desenvolve-se uma carga pela dissociação de grupos funcionais da superfície ou pela adsorção de íons da solução (Fuerstenau et alii, 1988). Mudanças no $\mathrm{pH}$ afetam o processo adsortivo, já que podem favorecer ou não a dissociação de grupos funcionais presentes nos sítios ativos do adsorvente. Sendo assim, é necessário determinar as propriedades eletroquímicas do adsorvente. Para tal é necessário identificar o PCZ do material, i.e., o ponto de carga zero. O PCZ pode ser definido como a atividade dos íons determinadores de potencial (que são os íons que constituem a carga superficial), em solução, quando essa carga superficial é zero (Fuerstenau et alii, 1988). Para os casos em que os íons determinadores de potencial são $\circ \mathrm{H}^{+} \mathrm{e} \circ \mathrm{OH}^{-}$, o conhecimento do $\mathrm{PCZ}$ permite prever a carga superficial do adsorvente de acordo com o pH: se $\mathrm{pH}<\mathrm{PCZ}$, os sítios superficiais estão protonados e a carga será positiva; se $\mathrm{pH}>\mathrm{PCZ}$, os grupos ionizáveis perdem seus prótons e a carga será negativa. O conhecimento da carga superficial do adsorvente e da carga do adsorvato permite predizer as interações eletrostáticas entre eles (repulsão ou atração), de forma que o valor do pH pode favorecer ou não o processo adsortivo.

O objetivo deste trabalho foi estudar a remoção de manganês utilizando o carvão ativado como adsorvente. Para tal, foi analisada a influência do tratamento térmico do carvão na sua capacidade de remoção de manganês, assim como foram determinados os pontos de carga zero (PCZ) dos carvões - com e sem tratamento -, procurando relacionar os resultados dos testes em batelada com os valores de PCZ encontrados.

\section{METODOLOGIA}

\subsection{Tratamento térmico de carvão}

Duas amostras de carvão de aproximadamente $10 \mathrm{~g}$ foram aquecidas separadamente por duas horas em uma estufa, uma a $150^{\circ} \mathrm{C}$ e outra a $200^{\circ} \mathrm{C}$. Após o aquecimento, cada amostra foi imediatamente resfriada em água destilada à temperatura ambiente, tendo sido filtrada e seca na sequência.

\subsection{Ensaio de adsorção de Mn em batelada}

Os ensaios em batelada foram feitos com solução sintética de $\mathrm{Mn}^{2+}(\sim 110 \mathrm{mg} / \mathrm{L})$ preparada a partir da dissolução de sulfato de manganês $\left(\mathrm{MnSO}_{4} \cdot 4 \mathrm{H}_{2} \mathrm{O}\right)$ em água deionizada. A solução tinha seu $\mathrm{pH}$ ajustado na faixa de 6,8-7,2 pela adição de cal hidratada, submetida a filtragem após o ajuste, sendo uma alíquota enviada para análise. Para cada ensaio foi utilizado um volume de $300 \mathrm{~mL}$ de solução, mantido a $25^{\circ} \mathrm{C}$ e sob agitação magnética, e uma massa de carvão de $3 \mathrm{~g}$, adicionada no início do teste. Quando necessário, foi utilizada uma solução de $\mathrm{NaOH}$ para controle de $\mathrm{pH}$ durante o teste. Alíquotas foram recolhidas após $2 \mathrm{~h}, 4$ h e 6 h, filtradas e enviadas para análise por espectroscopia de absorção atômica para a determinação da concentração de $\mathrm{Mn}$.

\subsection{Determinação de área superficial}

A determinação de área superficial dos três carvões foi feita com auxílio do equipamento NOVA 2200, da Quantachrome. O gás utilizado foi o $\mathrm{N}_{2}$ e os dados de pressão de vapor foram ajustados pelo modelo BET. 
2.4 Determinação do PCZ do carvão pelo método "drift" (método potenciométrico, ou da deriva)

Este método, usado por Prahas et alii (2008), entre outros, consiste na adição do material a soluções de um sal ajustadas em uma faixa de $\mathrm{pH}$ pré-determinada. $\mathrm{O}$ pH de cada uma se altera até atingir o equilíbrio, exceto no ponto em que o pH for o $\mathrm{PCZ}$. Foi utilizada uma solução de $\mathrm{KCl}$ $0,01 \mathrm{~mol} / \mathrm{L}$, assumindo que este seria um eletrólito indiferente ao carvão, ou seja, que não sofreria adsorção, de forma que os íons determinadores de potencial fossem apenas $\mathrm{H}^{+}$e $\mathrm{OH}^{-}$. A solução foi distribuída em 8 frascos, $100 \mathrm{~mL}$ em cada. Após o ajuste do pH, através da adição de soluções de $\mathrm{HCl}$ ou $\mathrm{NaOH}$, foi adicionado em cada frasco 0,3 g de carvão sem tratamento, e as soluções foram agitadas por 45 horas em um shaker horizontal da IKA Labortechnik, modelo HS 250 basic. Ao final, o pH de cada solução foi medido e comparado ao pH inicial. Os PCZ's dos carvões tratados a 150 e $200^{\circ} \mathrm{C}$ também foram determinados por este método.

\subsection{Determinação do PCZ do carvão pelo método de adição de sólido seco}

Neste método, o material testado é gradativamente adicionado a uma solução eletrolítica, e o pH é registrado após cada adição. Como ocorre adsorção dos íons determinadores de potencial pelo material, a atividade desses íons em solução se deslocará em direção ao PCZ (Fuerstenau et alii, 1988). Utilizou-se uma solução de $\mathrm{KCl}(0,01 \mathrm{~mol} / \mathrm{L})$. Partiu-se de dois pontos, um alcalino e outro ácido, obtidos pelo ajuste de $150 \mathrm{~mL}$ da solução com $\mathrm{NaOH}$ e $\mathrm{HCl}$, respectivamente. Foi adicionado um total de $4 \mathrm{~g}$ de carvão não tratado em cada solução, e o pH era medido 5 minutos após cada adição.

\section{RESULTADOS E DISCUSSÃO}

\subsection{Ensaios em batelada}

A escolha do $\mathrm{pH}$ de teste foi baseada em estudos anteriores. Kuhr et alii (1997) estudaram a adsorção de diferentes metais em um carvão de baixa pureza, e só obtiveram resultados satisfatórios para pH superior a 3,5. Além disso, estabeleceram a energia de ativação da adsorção e obtiveram um resultado compatível com uma adsorção química, ideia levantada em diversos trabalhos para sistemas carvão-íon metálico. Hayashi e Li (2004) apresentaram um estudo sobre um 'brown coal' típico da Austrália, reunindo informações de diversos autores. O mecanismo proposto de adsorção é o de troca iônica, através da dissociação de $\mathrm{H}^{+}$de grupos funcionais ácidos e de $\mathrm{Na}^{+}$de carboxilatos. Em pH baixo, poucos grupos funcionais ácidos iriam se dissociar, apenas carboxílicos. Em pH mais alto, grupos fenólicos também se dissociariam. Outro ponto importante a ser considerado é que em $\mathrm{pH}$ baixo ocorre aumento das interações entre átomos de hidrogênio, tornando a estrutura do carvão 'rígida' e dificultando o processo de adsorção. De acordo com os autores acima, aumentando-se o pH, haverá menos interações entre hidrogênios e mais grupos carboxílicos flexíveis, e o carvão assume uma estrutura 'flexível', mais propensa à adsorção. Portanto, de uma forma geral, quanto maior o pH, maior a capacidade de adsorção do carvão. Diante do exposto, dos limites de $\mathrm{pH}$ estabelecidos pelo CONAMA e dos gastos envolvidos com 
ajuste através de cal, optou-se por trabalhar em uma faixa próxima à neutralidade. Os dados referentes aos ensaios em batelada realizados em $\mathrm{pH}$ neutro se encontram na Tabela 1.

Tabela 1 - Valores de pH, concentração de Mn na solução residual e tempo de reação mostrando a influência do tratamento do carvão na remoção de $\mathrm{Mn}$.

\begin{tabular}{cccc}
\hline Amostra & Tempo (h) & pH & {$[\mathbf{M n}](\mathbf{m g} / \mathbf{L})$} \\
\hline Sem tratamento & 0 & 5,48 & 74,0 \\
Sem tratamento & 2 & 6,94 & 22,7 \\
Sem tratamento & 4 & 6,85 & 23,5 \\
Sem tratamento & 6 & 7,04 & 20,3 \\
\hline Tratada a $150^{\circ} \mathrm{C}$ & 0 & 5,52 & 79,0 \\
Tratada a $150^{\circ} \mathrm{C}$ & 2 & 6,94 & 36,2 \\
Tratada a $150^{\circ} \mathrm{C}$ & 4 & 6,94 & 37,0 \\
Tratada a $150^{\circ} \mathrm{C}$ & 6 & 6,94 & 36,0 \\
\hline Tratada a $200^{\circ} \mathrm{C}$ & 0 & 5,35 & 78,3 \\
Tratada a $200^{\circ} \mathrm{C}$ & 2 & 7,08 & 48,1 \\
Tratada a $200^{\circ} \mathrm{C}$ & 4 & 6,99 & 41,5 \\
Tratada a $200^{\circ} \mathrm{C}$ & 6 & 6,98 & 43,0 \\
\hline
\end{tabular}

A Tabela 1 mostra que de fato ocorre a remoção do manganês (II), mas sua concentração ainda está acima do limite permitido para descarte $(1 \mathrm{mg} / \mathrm{L})$. Além disso, o tratamento térmico por aquecimento mostrou-se inadequado para a remoção do metal, já que quanto maior a temperatura de tratamento menor a eficiência na retirada do $\mathrm{Mn}$ em solução, ou seja, o carvão não tratado foi o que obteve o menor valor de $\mathrm{Mn}$ em solução, enquanto o carvão tratado a $200{ }^{\circ} \mathrm{C}$ obteve o maior valor mínimo. $\mathrm{O}$ carvão tratado a $150{ }^{\circ} \mathrm{C}$ apresentou um resultado intermediário, comprovando a coerência dos resultados.

Este resultado é consistente com aquele obtido para o 'brown coal' por Murakami et alii (2001), que relataram a diminuição da capacidade de adsorção com o tratamento térmico. Após realizarem análises de infravermelho nas amostras tratadas, constataram a decomposição de grupos carboxílicos a partir de $150{ }^{\circ} \mathrm{C}$, sendo que quanto maior a temperatura de tratamento, maior a decomposição. Naturalmente, a diminuição desses grupos diminui a adsorção, de acordo com o mecanismo de troca iônica considerado anteriormente. Além disso, como a decomposição ocorre aleatoriamente, a probabilidade de existência de dois desses grupos adjacentes diminui ainda mais, sendo que tal adjacência é uma condição necessária para adsorção de um cátion divalente, como é o caso do $\mathrm{Mn}^{2+}$. Figueiredo et alii (1998) também observaram decréscimo gradual de todos os grupos superficiais oxigenados mediante aquecimento, embora tenham utilizado temperaturas maiores que as do presente trabalho. Os autores apontam que o aumento de grupos superficiais pode ser obtido por tratamento oxidativo com ácido nítrico.

\subsection{Avaliação da área superficial}

Existem várias técnicas para caracterizar a estrutura porosa dos adsorventes, sendo as mais utilizadas as de adsorção física de gases. Para a determinação da área superficial geralmente 
emprega-se o $\mathrm{N}_{2}$ e os dados de equilíbrio da pressão de vapor são ajustados pelo modelo BET. $\mathrm{O}$ modelo BET não é o mais indicado para materiais microporosos, tais como a maioria dos carvões ativados, pois não prevê a condensação capilar e, por isso, não se aplica a microporos; porém, é muito conhecido, e serve como comparação entre adsorventes. Assim, os valores de área superficial mostrados na Tabela 2 são referentes apenas a macro e mesoporos:

Tabela 2 - Área superficial para cada amostra de carvão ativado investigada.

\begin{tabular}{cc}
\hline Amostra & Área superficial específica $\left(\mathrm{m}^{2} / \mathbf{k g}\right)$ \\
\hline Carvão sem tratamento & 1038660,4 \\
Tratado a $150^{\circ} \mathrm{C}$ & 1055374,0 \\
Tratado a $200^{\circ} \mathrm{C}$ & 1056230,4 \\
\hline
\end{tabular}

Como se pode observar, os valores de área específica são muito próximos para as três amostras, indicando que o tratamento térmico praticamente não influencia nessa propriedade, apesar do ligeiro aumento medido. Além disso, esses resultados reforçam a ideia de que a diferença de remoção do manganês pelos três carvões está relacionada a propriedades químicas, e não físicas, do adsorvente.

\subsection{Avaliação do PCZ}

\subsubsection{Método "Drift"}

Com o intuito de conhecer o comportamento eletroquímico das amostras no pH de teste, procurou-se determinar o PCZ de cada uma delas. Os dados referentes aos ensaios pelo método "Drift" encontram-se apresentados na Figura 1. Para determinar os pontos de igualdade entre $\mathrm{pH}$ inicial e $\mathrm{pH}$ final, foram ajustadas curvas representadas por polinômios de $4^{\circ}$ grau. Assim, foi possível determinar matematicamente tal igualdade. Para o carvão não tratado o PCZ foi de 5,09; para o carvão tratado a $150{ }^{\circ} \mathrm{C}$ foi de 5,85 ; e para o carvão tratado a $200{ }^{\circ} \mathrm{C}$ foi de 5,75 . Na Figura 1 foi traçada a reta que representa $\mathrm{pH}_{\mathrm{i}}=\mathrm{pH}_{\mathrm{f}}$ para melhor visualização dos $\mathrm{PCZ}$ 's, onde as curvas interceptam a reta.

\subsubsection{Método de adição de sólido seco}

Os dados deste método representando o pH da solução em função da massa de carvão adicionada encontram-se na Figura 2 e representam somente o carvão sem tratamento. É importante destacar que o método de adição de sólido seco não é rigoroso, sendo utilizado essencialmente para corroborar com um resultado obtido anteriormente por um método mais preciso, e por isso foi aplicado somente a uma amostra.

Pode-se observar pelos resultados mostrados na Figura 2 que o PZC obtido foi de 4,63. As curvas de pH ácido e básico foram ajustadas por funções exponenciais ou curvas suaves, e o PCZ foi tomado como valor aproximado da média entre as assíntotas das duas curvas. $O$ valor encontrado é razoavelmente próximo àquele obtido pelo método "drift", validando o resultado encontrado para o carvão sem tratamento. 


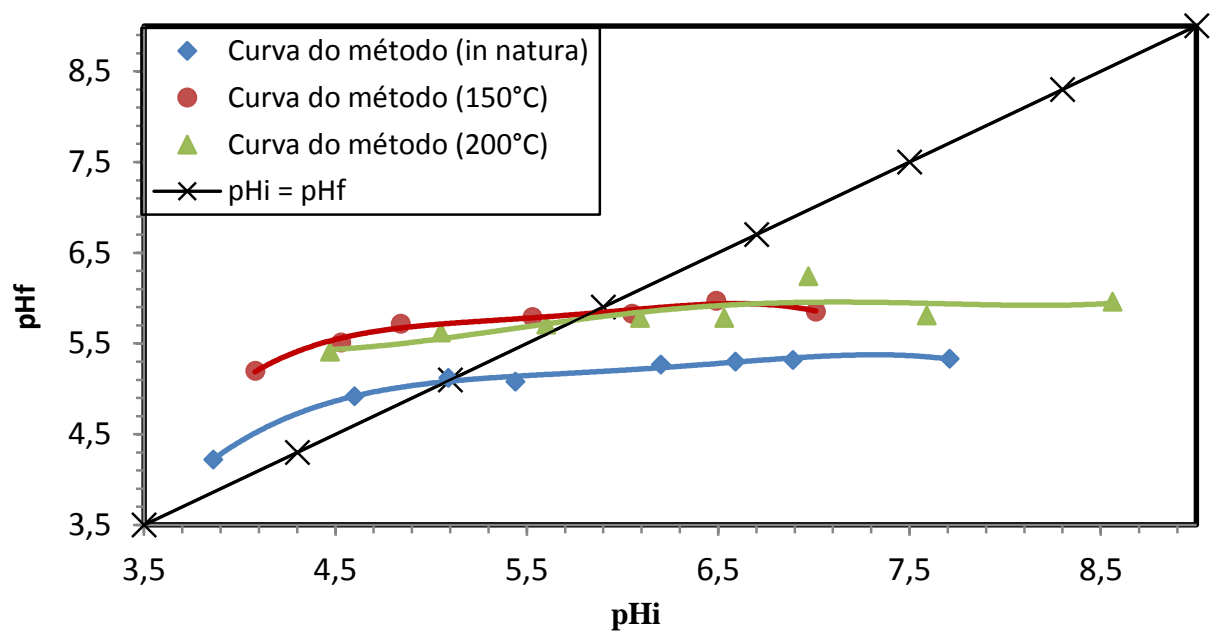

Figura 1 - Avaliação do PCZ utilizando-se o método "Drift".

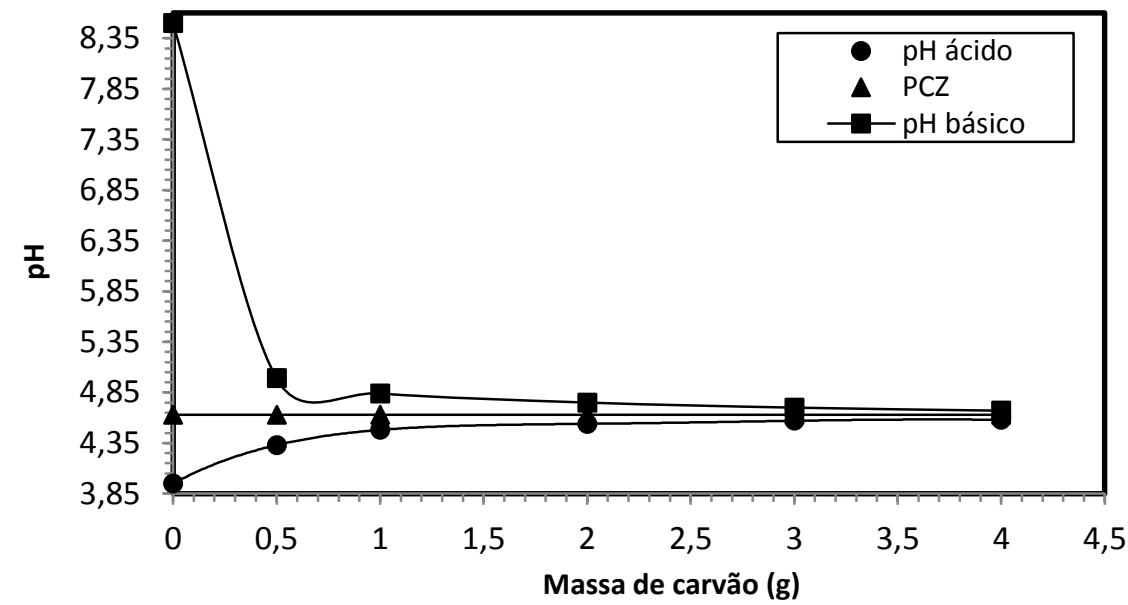

Figura 2 - Avaliação do PCZ utilizando-se o método de adição de sólido seco para o carvão sem tratamento partindo-se de dois pontos, um ácido e outro básico.

\section{CONCLUSÃO}

O valor de PCZ encontrado para o carvão sem tratamento foi de 5,09, garantindo que no $\mathrm{pH}$ em que foram realizados os testes em batelada sua carga superficial era negativa, e portanto capaz de atrair o $\mathrm{Mn}^{2+}$ livre. A capacidade adsortiva do carvão em relação ao manganês foi comprovada pela queda de concentração do metal em solução. As duas amostras de carvão tratadas em temperaturas diferentes apresentaram valores de PCZ maiores que a amostra sem tratamento, o que indica uma atração entre os íons $\mathrm{Mn}^{2+}$ e a superfície do adsorvente inferior ao carvão in natura. Esses valores de PCZ ficaram muito próximos entre si, se considerados erros experimentais, com um valor médio de 5,8. Essa proximidade, também encontrada nas áreas superficiais específicas, indica que a capacidade de remoção do metal está relacionada principalmente às propriedades químicas do adsorvente, ou seja, é dependente do mecanismo de adsorção. A queda da capacidade adsortiva com o tratamento térmico foi atribuída à decomposição de grupos carboxílicos. Do ponto de vista prático, a não necessidade do tratamento térmico é vantajosa por questões operacionais e econômicas. 
Por fim, apesar de comprovada a capacidade adsortiva do carvão, os resultados em batelada mostraram que sua ação não foi suficiente para que a solução atingisse o limite de descarte de manganês permitido pelos órgãos responsáveis nas condições de teste sugeridas e, por isso, o carvão não foi testado no efluente real. De qualquer forma, espera-se atender a legislação mediante o uso de carvão ativado em colunas operadas continuamente, como se verificou em estudo de remoção de Mn empregando-se carvão de ossos bovinos (Sicupira, 2012).

\section{REFERÊNCIAS BIBLIOGRÁFICAS}

1. FIGUEIREDO, J.L., PEREIRA, M.F.R., FREITAS, M.M.A., ÓRFÃO, J.J. Modification of the surface chemistry of activated carbons. Carbon, v.37, p. 1379-1389, 1999.

2. FUERSTENAU, D.W., ROSENBAUM, J.M., YOU, Y.S. Electrokinetic Behavior of Coal. Energy \&Fuels, v.2, p. 241-245, 1988.

3. GUILARDUCI, V.V.S., MESQUITA, J.P., MARTELLI, P.B. Adsorção de fenol sobre carvão ativado em meio alcalino. Química Nova, v.29, n.6, p. 1226-1232, 2006.

4. HAYASHI, J., LI, C.Z. Structure and Properties of Victorian Brown Coal. Advances in the Science of Victorian Brown Coal, Elsevier Ltd, Chapter 2, 2004.

5. KUHR, J.H., ROBERTSON, J.D., LAFFERTY, J., WONG,A.S. Ion Exchange Properties of a Western Kentucky Low-Rank Coal. Energy\&Fuels, v.11, p. 323-326, 1997.

6. MADEIRA, V.S., JOSÉ, H.J., MOREIRA, R.F.P.M. Utilização de carvão adsorvente para a remoção de íons ferro em águas naturais. http://www.enq.ufsc.br, 2008.

7. MISHRA, S.B., MISHRA, A.K., KHAN, M.A. Decolourization of pulp and paper mill effluents using heat-treated coal: a comparison with activated charcoal. Environ. Chem. Lett., v.8, p. 231-235, 2010.

8. MURAKAMI, K., YAMADA, T., KAGA, K., FUDA, K., MATSUNAGA, T. Cation exchange properties of heat-treated Australian brown coal: influences of pre-exchanged calcium ions. Colloids and Surfaces, v.193, p. 153-159, 2001.

9. PRAHAS, D., KARTIKA, Y., INDRASWATI, N., ISMADJI, S. Activated carbon from jackfruit peel waste by $\mathrm{H}_{3} \mathrm{PO}_{4}$ chemical activation: Pore structure and surface chemistry characterization. Chemical Engineering Journal, v.140, p. 32-42, 2008.

10. SANTOS, E.A., LADEIRA, A.C.Q. Recovery of Uranium from Mine Waste by Leaching with Carbonate-Based Reagents. Envir. Science \& Technology, v.45, p.3591-3597, 2011.

11. SICUPIRA, D.C. Remoção de manganês de drenagem ácida de mina utilizando carvão de osso. Belo Horizonte, 2012. Dissertação de Mestrado-PPGEM-UFMG, p.76, 2012. 